\title{
EDITORIAL
}

\section{Hello and welcome to Spinal Cord Series and Cases}

Spinal Cord Series and Cases (2017) 3, 17023; doi:10.1038/ scsandc.2017.23; published online 18 May 2017

We are starting with a fresh new cover in order to emphasize the direction of Spinal Cord Series and Cases. The title of the statue is 'Strength with Grace' (La forza con la grazia). This statue was created by John Ditunno, a well-loved ISCOS member and pioneer spinal cord injury $(\mathrm{SCl})$ researcher and leader who began sculpting after transitioning from a full time academic career. He completed a statue of a male wheelchair basketball player for the $\mathrm{SCl}$ center in Rome in 2007 and was commissioned by John Steeves of ICORD in Canada to create a similar statue based on a woman for ICORD. The ball was raised from a passing position to a shooting pose, which presented an additional challenge due to the risk of the arms breaking from the weight of the elevated ball. The design in clay and carving of a 9-inch wooden model took 6 months and the execution in marble approximately 12 weeks, working 8-10 h a day. The statue is made of white Carrara, the marble used by Michelangelo.

As the new Editor-in-Chief of Spinal Cord Series and Cases, I plan to emphasize the dynamic nature of spinal cord injury and the achievements of our population. We will focus on publishing case reports and series, pilot studies, and publications related to practical and current topics affecting the lives of persons living with spinal cord disorders and diseases. Over the next year, I will be adding a new editorial board and focusing on making SCSC a creative, practical and dynamic educational tool for clinicians in the area of spinal cord injury and disorders. With the journal I plan to include topics of special interest in addition to articles submitted by our authors. Moreover, I would like to develop a linkage to other forms of education pertaining to the field of $\mathrm{SCl} / \mathrm{D}$.

I would like to explore those areas that are less amenable to publication in our sister journal Spinal Cord. These may be issues related to regional or universal social, environmental, psychological, vocational, recreational, economic, health and wellness issues and of course medical concerns of persons with SCl/Ds. I think it is important for us to know not only the medical concerns of persons with $\mathrm{SCls}$ but how they live their lives under the rapidly changing conditions in our world. I would also like to highlight case reports of persons or groups of persons with $\mathrm{SCls}$ that do extremely well and address concerns related to caring for family and professional providers of persons with SCls. Moreover, I think it is important that as an educational forum, when communicating we use the terminology that has been developed by experts over the past few years. Therefore, I strongly encourage authors to ensure that they use the International Standards for Neurologic Classification of $\mathrm{SCl}$, the International Standards to Document Remaining Autonomic Function after $\mathrm{SCl}$ and the International Spinal Cord Injury Data sets when submitting articles. In order to structure these broader submissions, we we will be adding a choice when submitting articles to say whether your article is of regional interest related to social, culture, economic or environmental issues or whether it may be related to wellness, or highlighting the data sets or standards. I would like to especially encourage and highlight these submissions and hope,

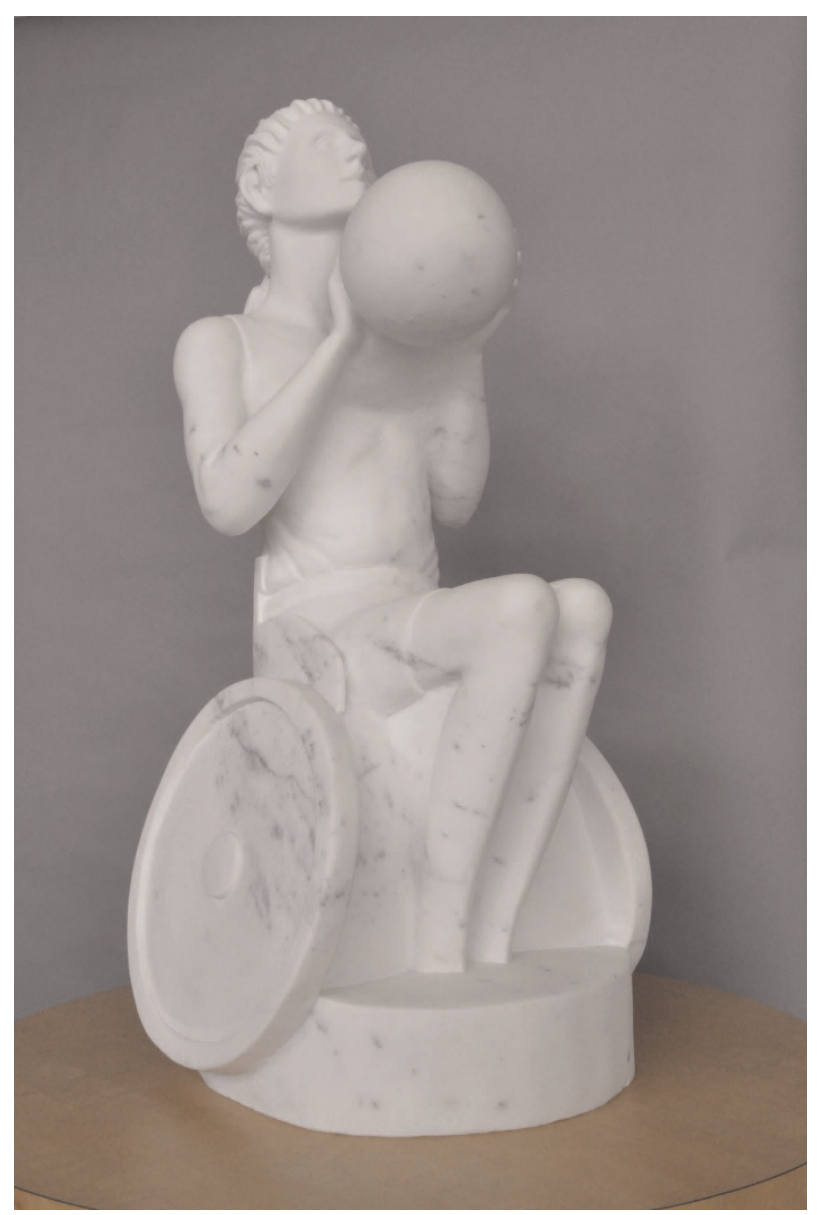

by 2019 , to make use of the data sets and autonomic standards required.

To conclude, I am delighted to serve as the new Editor-In-Chief for SCSC; however, I need your assistance to make this journal a vehicle for all to use. I look forward to receiving positive suggestions from the readership and will consider all topics related to $\mathrm{SCl}$ on the table. I am actively working on putting together a new editorial board and if you have an interest in serving or if you have suggestions for topics that the journal can cover, please write to me at spinalcordmd@live.com and I would be happy to hear your suggestions. Additionally, we will be moving to a new editorial platform this year and will be changing the journal cover when this happens, so if you have a picture or piece of artwork that you believe personifies the lives of persons with $\mathrm{SCls}$ please send it to me!

Marcalee Sipski Alexander Physical Medicine and Rehabilitation, VAMC, Birmingham, Alabama, USA

E-mail: spinalcordmd@live.com 